\section{Extraction of Two Active Polysaccharides from the Yeast Cell Wall}

\section{Gang L. Huang}

College of Chemistry, Chongqing Normal University, Chongqing 400047, China.

E-mail: huangdoctor226@163.com

Z. Naturforsch. 63c, 919-921 (2008);

received June 9/July 9, 2008

Yeast cell wall matrix particles are composed entirely of $\beta$-glucan and mannoprotein. Alkali-insoluble $(1 \rightarrow 3)$ $\beta$-D-glucan was extracted from the yeast cell wall by an alkaline-acid method. IR spectra analysis showed that the product was chemically pure glucan, that is to say, it contained no other carbohydrates and proteins. So, the alkaline-acid method was ideal for extracting $(1 \rightarrow 3)-\beta$ D-glucan from the yeast cell wall. We also purified and analyzed mannan oligosaccharides by the dilute alkaliSevage method from the yeast cell wall.

Key words: $(1 \rightarrow 3)-\beta$-D-Glucan, Mannan Oligosaccharides, Yeast Cell Wall

\section{Introduction}

The yeast cell wall is a nonspecific stimulator of the immune system of both man and animals (Cabib et al., 2001). Yeast is applied in the wine industry: its ability to bind undesirable components allows to prevent and cure stuck fermentations. The yeast cell wall consists of $30-60 \%$ polysaccharides ( $\beta$-glucan and mannan oligosaccharides) (Huang et al., 2004, 2005), 15-30\% proteins, 5-20\% lipids and a small amount of chitin. Most of the protein is linked to the mannan oligosaccharides and is referred to as the mannoprotein complex. $\beta$-Glucan can stimulate the cells of the immune system (macrophages) and helps to overcome bacterial infections. Mannan oligosaccharide has been demonstrated to prevent diarrhoea in weaning pigs. It binds to pathogenic bacteria in the gut and carries them through and out of the intestinal tract. Mannan oligosaccharide also has prebiotic activity and can serve as a nutrient source for the growth of beneficial bacteria in the colon. Based on the important biological functions of yeast cell walls, the extraction methods for alkali-insoluble $(1 \rightarrow 3)$ - $\beta$ D-glucan and mannan oligosaccharide from the yeast cell wall have been studied.

\section{Results and Discussion}

IR spectrum analysis of $(1 \rightarrow 3)-\beta$-D-glucan

The IR spectrum of $(1 \rightarrow 3)$ - $\beta$-D-glucan (Fig. 1$)$ shows the typical spectral pattern of $(1 \rightarrow 3)-\beta$-Dglucan, that is to say, it contains absorption bands arising from the $v(\mathrm{CC})$ and the $v(\mathrm{COC})$ stretching vibrations at $1161 \mathrm{~cm}^{-1}$, two partially overlapped bands at 1078 and $1044 \mathrm{~cm}^{-1}$ attributable to ring and $\mathrm{C}-\mathrm{OH}$ side group stretchings, a band at $891 \mathrm{~cm}^{-1}$ assigned to the $\beta$-glycosidic $\mathrm{C}_{1}-\mathrm{H}$ deformation mode, and the highest intensity of the $v(\mathrm{OH})$ band at lower frequency $\left(3380 \mathrm{~cm}^{-1}\right)$. The presence of amide I and amide II bands at 1654 and $1637 \mathrm{~cm}^{-1}$ accords with the residual protein content $(1.6 \%)$ of the glucan.

\section{IR spectrum analysis of mannan oligosaccharides}

Fig. 2 shows the IR spectrum of mannan oligosaccharides. It contains absorption bands arising from the $v(\mathrm{CC})$ and the $v(\mathrm{COC})$ stretching vibrations at $1140 \mathrm{~cm}^{-1}$, a band at $846 \mathrm{~cm}^{-1}$ assigned to the $\alpha$-glycosidic $\mathrm{C}_{1}-\mathrm{H}$ deformation mode, and the highest intensity of the $v(\mathrm{OH})$ band at lower frequency $\left(3456 \mathrm{~cm}^{-1}\right)$. The presence of a carbonyl group band at $1688 \mathrm{~cm}^{-1}$ proved to have the residual protein in the mannan oligosaccharide sample.

\section{The alkaline-acid method for extracting} $(1 \rightarrow 3)-\beta$-D-glucan and the dilute alkali-Sevage method for extracting mannan oligosaccharides

Yeast cell wall matrix particles are composed entirely of $\beta$-glucan and mannoprotein. $(1 \rightarrow 3)-\beta$ D-Glucan that was extracted is alkali-insoluble, but the mannoprotein is alkali-soluble (Fujii et al., 1999). In the process of the alkaline-acid method, we used $4 \%$ phosphoric acid to remove $(1 \rightarrow 6)$ $\beta$-D-glucan, which is linked to alkali-insoluble $(1 \rightarrow 3)-\beta$-D-glucan (Bron, 1996). The Sevage method was used to remove the residual protein.

\section{Materials and Methods}

\section{Materials}

Yeast cell walls were purchased from Anqi Company (Yichang, China). IR spectra were recorded with an FT-IR apparatus, and wavenumbers are reported in $\mathrm{cm}^{-1}$. 


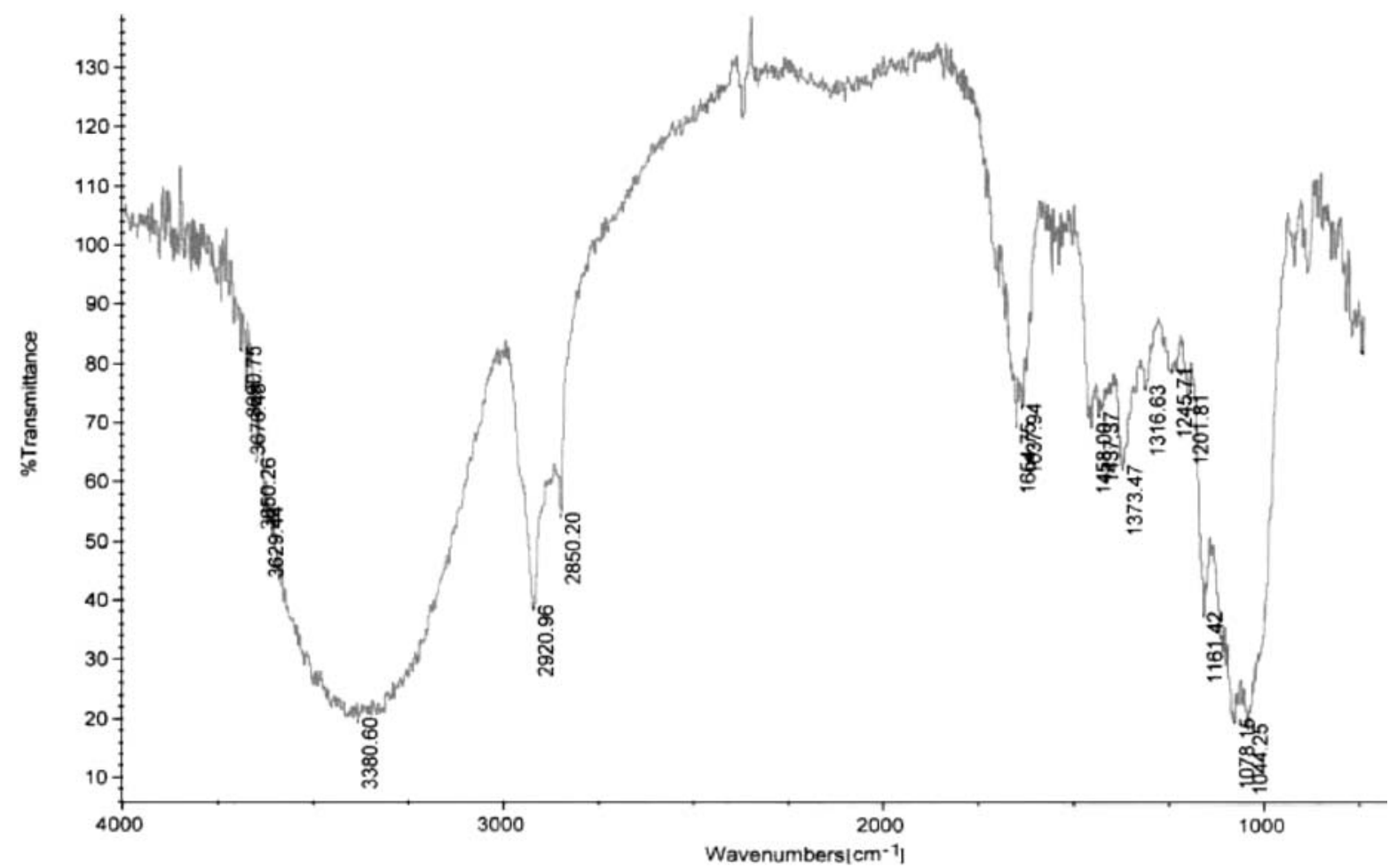

Fig. 1. IR spectrum (in $\mathrm{KBr}$ ) of alkali-insoluble $(1 \rightarrow 3)-\beta$-D-glucan.

Extraction of alkali-insoluble $(1 \rightarrow 3)-\beta$-D-glucan

Alkali-insoluble $(1 \rightarrow 3)$ - $\beta$-D-glucan was obtained from yeast cell walls by extraction with $6 \% \mathrm{NaOH}$ at $60{ }^{\circ} \mathrm{C}$ for $4 \mathrm{~h}$. Distilled water was added to the dispersion, and the insoluble part, after stirring for $30 \mathrm{~min}$, was collected by centrifugation. The sediment was suspended in $3 \% \mathrm{NaOH}$ and heated at $90{ }^{\circ} \mathrm{C}$ for $2 \mathrm{~h}$. The insoluble material was recovered by centrifugation, washed three times with distilled water, and subsequently extracted twice with $4 \%$ phosphoric acid at room temperature for $2 \mathrm{~h}$. The insoluble residue, representing the cell wall $(1 \rightarrow 3)-\beta$-D-glucan, was separated by centrifugation, resuspended in distilled water, and decanted with water until $\mathrm{pH} 7$. The aqueous suspension was taken for the recovery of the particulate glucan using the technique of spraying dryness. The yield was $13.5 \%$.

\section{Extraction of mannan oligosaccharides}

The water-soluble mannan oligosaccharides were obtained from $5 \mathrm{~g}$ yeast cell walls by extraction with $1 \% \mathrm{NaOH}(50 \mathrm{~mL})$ at $100{ }^{\circ} \mathrm{C}$ for $2 \mathrm{~h}$, cooling and neutralizing to $\mathrm{pH} 7$ with dilute $\mathrm{HCl}$ solution. After filtration, the mannan oligosaccharides were precipitated by adding $200 \mathrm{~mL}$ (4 volumes) of absolute ethanol. The precipitate was washed with absolute ethanol and diethyl ether, respectively. The residual protein was further removed by the Sevage method (Staub, 1965).

\section{Acknowledgements}

This work was supported by the Doctor Startup Foundation of Chongqing Normal University (No. 07XLB025) and Chongqing Education Commission Foundation (No. KJ080810), China. 


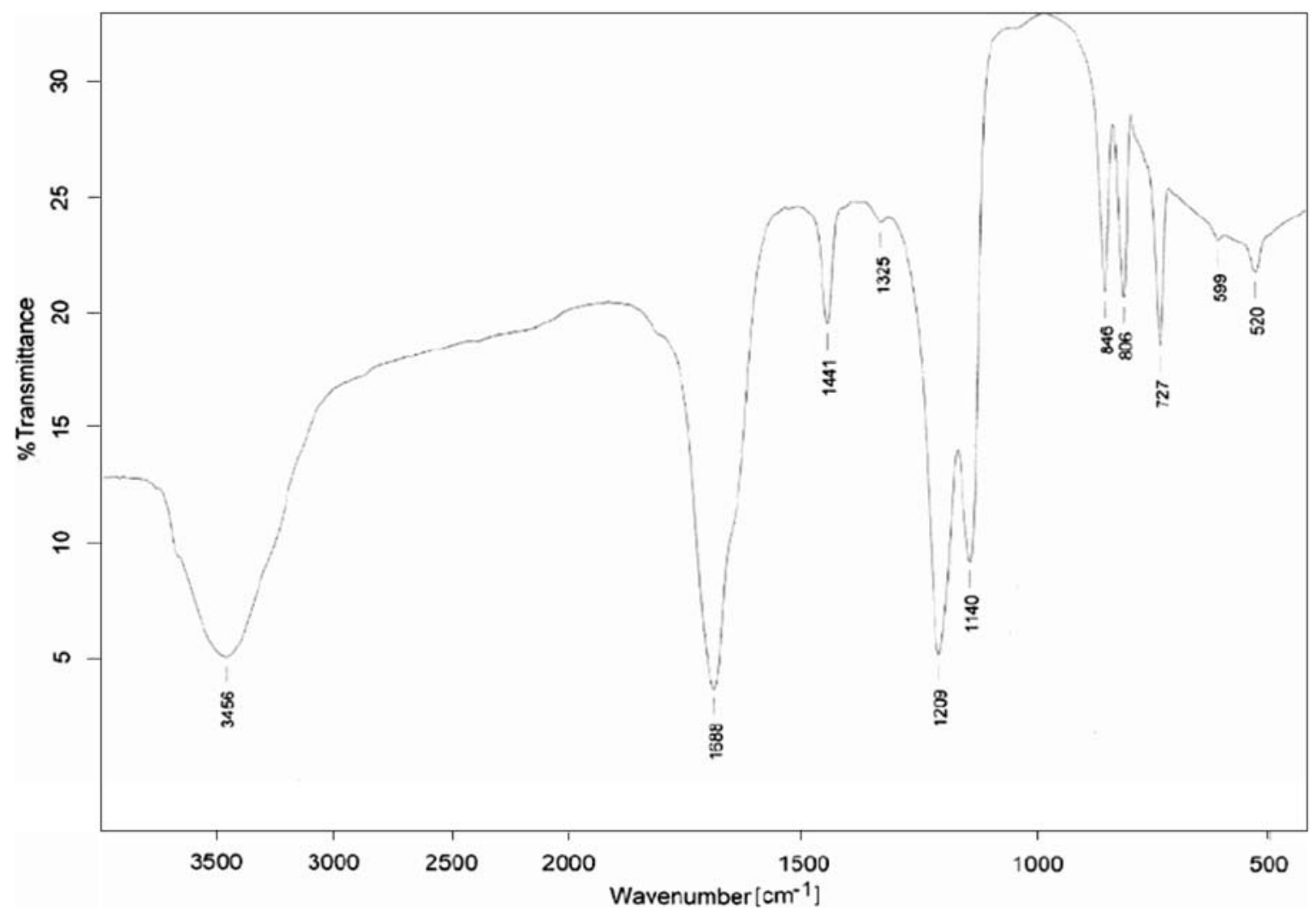

Fig. 2. IR spectrum (in $\mathrm{KBr}$ ) of the mannan oligosaccharides.

Bron A. D. (1996), Patent, US 5576015.

Cabib E., Roh D. H., Schmidt M., Crotti L. B., and Varma A. (2001), The yeast cell wall and septum as paradigms of cell growth and morphogenesis. J. Biol. Chem. 276, 19679-19682.

Fujii T., Shimoi H., and Iimura Y. (1999), Structure of the glucan-binding sugar chain of Tip1p, a cell wall protein of Saccharomyces cerevisiae. Biochim. Biophys. Acta 1427, 133-144.

Huang G. L., Liu M. X., and Mei X. Y. (2004), Synthesis, $(1 \rightarrow 3)$ - $\beta$-D-glucanase-binding ability, and phytoalexin- elicitor activity of a mixture of 3,4-epoxybutyl $(1 \rightarrow 3)$ $\beta$-D-oligoglucosides. Carbohydr. Res. 339, 1453-1457. Huang G. L., Liu M. X., and Mei X. Y. (2005), Studies on the hydrolytic condition of $\beta-1,3$ glucan from yeast by fluorophore-assisted carbohydrate electrophoresis. Anal. Lett. 38, 477-485.

Staub A. M. (1965), Removal of proteins: Sevage method. Methods Carbohydr. Chem. 5, 5-6. 